\title{
Weldability of Aluminum to Mild steel using Friction Welding Process
}

\author{
Ch. Indira Priyadarsini ${ }^{1}$, Akshay Gadipalli ${ }^{2}$, Shri Sai Pranav Thalla ${ }^{3}$ \\ Mechanical Department ${ }^{1,2,3}$, CBIT $^{1,2,3}$ \\ Email: med.amere13@gmail.com ${ }^{1}$ akshaygadipalli@gmail.com ${ }^{2}$
}

\begin{abstract}
This paper involves live study of the different materials that are being welded on a Thomson frictionwelding machine. The material or the metal rods are mounted on the machine at its aligning points which include a leftward chuck for holding the stationary metal bar and the rightward chuck which holds the other metal bar which is to be welded to the previously placed bar. While rotating pressure is applied on the metal bars and the friction between these two bars creates the semi liquid phase of the two metals which are then forged again in this state to form weld at the faying surfaces. The parameters of the different phases like pre heating, forging, rotational speed, diameter viz. Dimensions of the metal bars that are being used to be welded together etc. During this process of friction welding is carried out.
\end{abstract}

Keywords-Friction Welding, Forging, Rotating Pressure, Metal bars.

\section{INTRODUCTION}

The project has the greater task of finding the different welding parameters required for a large number of materials that are currently being used in the market for various purposes and those alloys or materials that are being tested for further developments for future requirements and uses. Hence the study finds a greater acceptance and a wider audience and will serve the necessity of a predetermined study for a Huge range of materials that undergo welding the study of the different welding parameters proves to be a great advantage especially in the heavy industry sector where faster production rates means greater benefits for the industry and the eventual development of the company as a whole.

According to the American Welding Society, the origins of friction welding date back to 1891 , when the first patent on the process was issued in the USA. More work progressed throughout Europe as more patents were issued from 1920 to 1944 and in the USSR in 1956. In the 1960's, friction welding was further developed in the USA by AMF, Caterpillar, and Rockwell International. Rockwell built its own machines to weld spindles to truck differential housings, AMF produced machines to weld steering worm shafts, and Caterpillar's machines welded turbochargers and hydraulic cylinders. Traditionally, friction welding is carried out by moving one component relative to the other along a common interface, while applying a compressive force across the joint. The friction heating generated at the interface softens both components, and when they become plasticized the interface material is extruded out of the edges of the joint so that clean material from each component is left along the original interface. The relative motion is then stopped, and a higher final compressive force may be applied before the joint is allowed to cool. Solid state welding processes are characterized by the absence of melting and the formation of narrow heat affected zone (HAZ), if any. The metallurgical properties are usually excellent and most of the processes can be mechanized or automated to be used as high as high production rate processes. The more widely used and industrially important processes in this category are friction welding and explosion or explosive welding; with both these processes are described herein friction welding one piece is rotated and the other is made to rub against it under an axial load resulting in increased friction, heat generation and joining when the pieces are brought to rest under sustained or enhanced axial load, as depicted below. This process has been used for joining thermoplastic polymers since 1945 but its first successful application for welding metals was reported from Russia in1956. [2]

Filler metal flux or shielding gas is not required in friction welding and the joint is similar in appearance to the ones produced by electrical resistance butt welding process of flash and upset welding. Normally cylindrical pieces like rod and tubes are welded by this process but its application can be extended to situations where in one of the components is symmetrical and can be rotated conveniently. Chudikov and Vill from Russia are credited with the successful application of friction welding to metals. The fundamental consideration of the process is of course, based on the well-known law that friction F, is proportional to the applied normal load, L. Pure aluminum is ideally suited for friction welding. Out of the large number of aluminum alloys and powder metallurgical materials available, there are still some whose suitability for welding has still to be tested. [1].The sliding velocity varies from zero at the center of the work piece to a maximum at the peripheral 


\section{Available online at www.ijrat.org}

surface and the radius at $2 / 3$ rd the diameter of the workplace is used for calculations. Longer heating times result in material for forging when the rotation is stopped. Excessive initial pressure results in excessive squeezing of the heated metal leaving only relatively cold metal to be forged when the forging pressure is applied. [2].The quick rise and the fluctuating nature of the curve is due to the change from marginal or boundary layer friction with $\mu=01$ to 0.2 to pure friction with $\mu>0.3$. The torque increases as the points of seizure increases and finally molten metal may appear at these points of contact and act as a lubricant and the temperature of the interface may rise to 900 $1100{ }^{\circ} \mathrm{C}$. [3] Controls by time sequence are found satisfactory for cases where constant surface condition cannot be assured and welds are of secondary importance. When time control is used, high rotational speeds are preferred. The speed for mild steel is selected on the basis of stock diameter and is given by the expression. [4]. If adequate pressure is available, it is possible to increase the capacity of a machine by using a beveling technique, as shown below. Welding variables, Three major variables in continuous drive friction welding are, Rotational speed, Axial pressure, Heating time. In dissimilar metal welds, low rotational speeds can minimize the formation of brittle intermetallic compounds; however in general for controlling weld quality, rotational speed is not considered as a critical parameter. [5]. One of the attractive features of friction welding is the metallurgical quality of the welds; the rapidity of heat generation produces an almost negligible heat affected zone. Due to good control or temperature and as the plastic metal is subjected to hot working during the heat phase, and to cold working during the forging phase, this result in a weld with extremely fine grain structure. [6]. For successful friction welding, the outer diameter of the work piece should not exceed the other by more than 1.33 times. The length projecting from the chuck should be $20-25 \mathrm{~mm}$. The clamped length of the component should not be less than the weld diameter.

When bars or tubes are welded to plates most of the material that forms the flash comes from the bar or tube; this is because there is less mass in the smaller section and therefore heat penetrates deep into it. [7]. Friction welding machines are required to control accurately three variables viz., axial thrust speed of rotation, degree of upset. Plain carbon and low alloy steels require a forge pressure of $15-30 \mathrm{~N} / \mathrm{mm} 2$. while tungsten steels are require pressure in the range of $225-400 \mathrm{~N} / \mathrm{mm} 2$.these latter values are comparable to the pressure used in flash butt welding. When the rate of application of pressure, by a hydraulic system is found to be low, it is replaced by a pneumatic system. [8]. If too much power is applied, the width of the shear zone of the metal increases. If the power applied is just above the threshold it will take a long time for the temperature to be reached and the heat affected zone will be wide. The most important variable is the unit pressure applied during rotation and the recommended values for some of the metals are given below. [9]

\section{SELECTION OF MATERIALS}

\subsection{Materials used in experiment}

Different types of metals can be used for friction welding process but as a part of our project we have chosen nonferrous metals like aluminum, copper, mild steel and brass. And the dimensions of the metals we have used are as shown in fig.

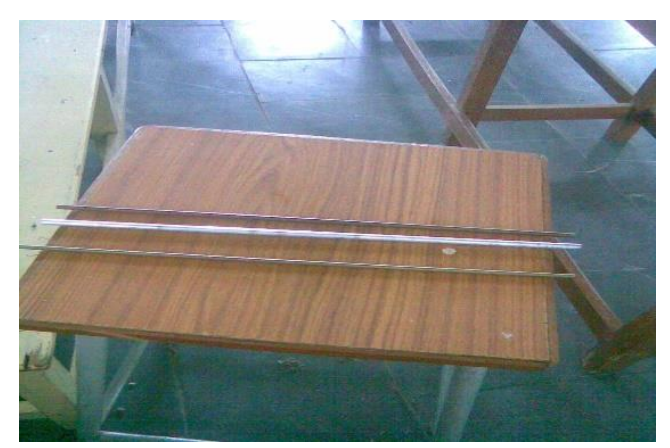

Fig.1. Materials used for friction welding (Aluminum, Brass, Copper)

Table: Material dimensions

\begin{tabular}{|c|c|c|}
\hline Length & Metal used & Diameter \\
\hline $200 \mathrm{~mm}$ & Aluminum & $9 \mathrm{~mm} \& 10 \mathrm{~mm}$ \\
\hline $200 \mathrm{~mm}$ & Mild Steel & $\mathrm{mm}$ \\
\hline
\end{tabular}

\subsection{Properties of Materials}

\begin{tabular}{|c|c|c|c|c|}
\hline & & & & \\
\hline $\mathrm{Cu}-0.1$, & $160-280$ & $660{ }^{\circ} \mathrm{C}$ & $\mathrm{H} 30$ & Aluminum \\
$\mathrm{Mn}-1.2$, & ${ }^{\circ} \mathrm{C}$ & & & \\
$\mathrm{Mg}-0.6$. & & & & \\
\hline $\mathrm{C}-0.17$, & $550-660$ & $970{ }^{\circ} \mathrm{C}$ & $\mathrm{BS} 970$ & Mild Steel \\
$\mathrm{Si}-0.3$, & ${ }^{\circ} \mathrm{C}$ & & & \\
$\mathrm{Mn}-0.8$, & & & & \\
$\mathrm{S}-<=$ & & & & \\
0.05, & & & & \\
$\mathrm{P}-<=0.04$. & & & & \\
\hline
\end{tabular}

Different types of metals can be used for this friction surfacing process according to their properties. Among different types of metals we have chosen four metals they are mild steel as the base metal for all and the aluminum, copper, brass to coat over mild steel.

\subsection{Properties of Aluminum}

The microstructure is shown in Fig.2 


\section{International Journal of Research in Advent Technology, Vol.7, No.5, May 2019 \\ E-ISSN: 2321-9637 \\ Available online at www.ijrat.org}

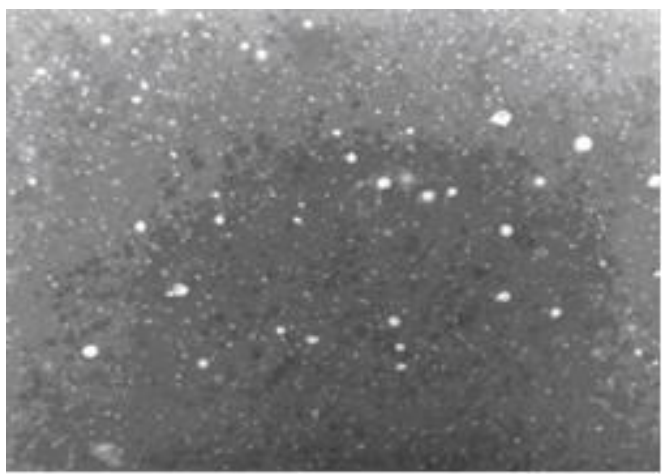

Fig.2: Microstructure of Aluminum

1. Weight: With a density of $2.7 \mathrm{~g} / \mathrm{cm} 3$, aluminum is approximately one third as dense as steel.

2. Strength: Aluminum alloys commonly have tensile strengths of between 70 and $700 \mathrm{Mpa}$. The range for alloys used in extrusion is $150-300 \mathrm{Mpa}$.

Unlike most steel grades, aluminum does not become brittle at low temperatures. Instead, it strength increases. At high temperatures, aluminum's strength decreases. At temperatures continuously above $100 \mathrm{oC}$, strength is affected to the extent that the weakening must be taken into account.

3. Linear expansion: Compared with other metals, aluminum has a relatively large coefficient of linear expansion. This must to be taken into account in some designs.

4. Malleability: Aluminum's superior malleability is essential for extrusion. With the metal either hot or cold, this property is also exploited in the rolling of strips and foils, as well as in bending and other forming operations.

5. Machining: Aluminum is easily worked using most machine methods- milling, drilling, cutting, punching and bending.

The energy input during machining is low. Aluminum is easy to machine using most machining methods.

6. Jointing: Features facilitating easy jointing are often incorporated into profile design. Welding (fusion welding, friction stir welding), bonding and taping are also used for jointing.

7. Conductivity: Aluminum is an excellent conductor of heat and electricity. An aluminum conductor weighs approximately half as much as a copper conductor having the same conductivity.

8. Reflectivity: Aluminum is a good reflector of both visible light and radiated heat.

9. Screening: Tight aluminum boxes can effectively exclude or screen electromagnetic radiation. The better conductivity of a material, the better shielding qualities.

10. Corrosion resistance: Aluminum reacts with the oxygen in the air to form an extremely thin layer of oxide. Though it is only some hundredths of a $\mu m$ thick (1 $\mu m$ is one thousandth of a millimeter), this layer is dense and provides excellent corrosion protection. The layer is self-repairing if damaged. Anodizing increases the thickness of the oxide layer and thus improves the strength of the natural corrosion protection. Aluminum is extremely durable in neutral and slightly acid environments. In environments characterized by high or low $\mathrm{pH}$ values, corrosion is rapid.

\subsection{Properties of Aluminum}

The microstructure is shown in Fig.3.

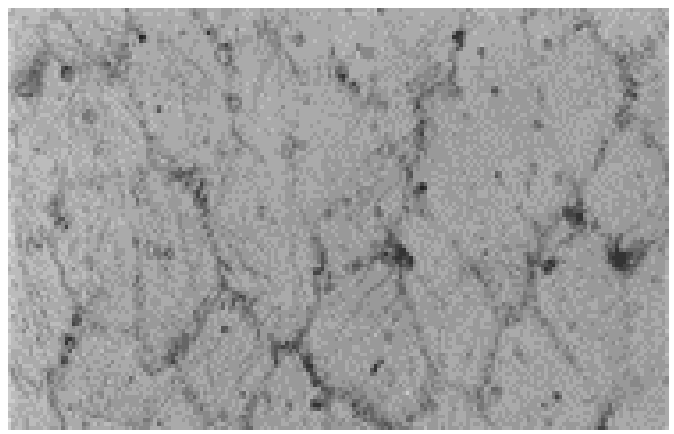

Fig.3: Microstructure of MS

Mild steel is the most common form of steel as its price is relatively low while it provides material properties that are acceptable for many applications. Low carbon steel contains approximately 0.05-0.15\% carbon and mild steel contains $0.16-0.29 \%$ carbon, therefore it is neither brittle nor ductile. Mild steel has a relatively low tensile strength, but it is cheap and malleable; surface hardness can be increased through carburizing. It is often used when large amount of steel is needed, for example as structural steel. The density of mild steel is $7,861.093 \mathrm{~kg} / \mathrm{m}^{3}(0.284 \mathrm{lb} / \mathrm{in})$ the tensile strength is a maximum of $500 \mathrm{MPa}(73,000$ psi) and the Young's modulus is $210,000 \mathrm{MPa}$ $(30,000,000)$. These trade terms are often used interchangeable to describe standard carbon steels used for structural purposes, a typical example being AS3679 grade 250 or grade 300.The term 'mild steel' is also applied commercially to carbon steels not covered by standard specifications. Carbon content of this steel may vary from quite low levels up to approximately $0.3 \%$. Generally, commercial 'mild steer' can be expected to be readily weldable and have reasonable cold bending properties but to specify 'mild steel' is technically in appropriate and should not be used as a term in engineering. 


\section{Available online at www.ijrat.org}

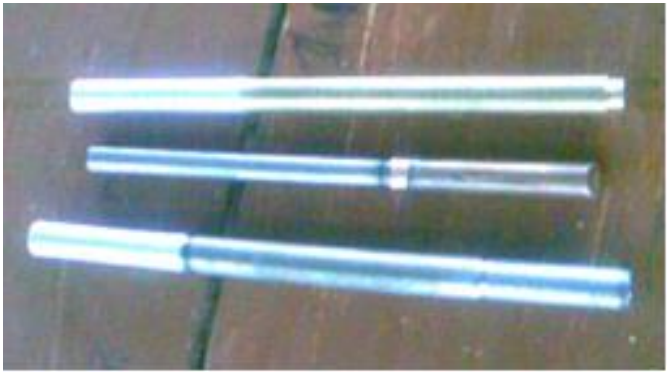

Fig.4: Welding of Dissimilar metals

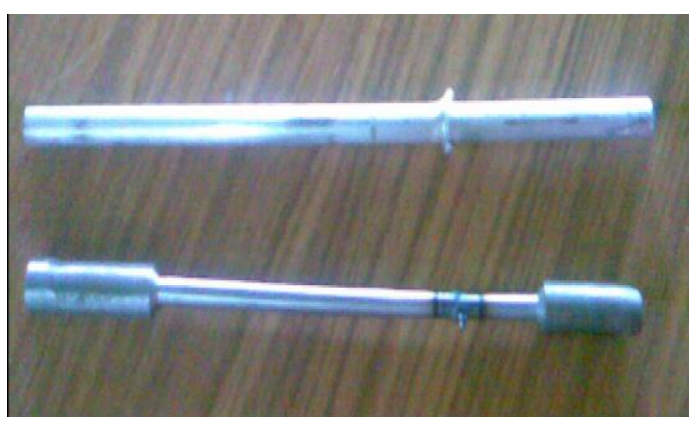

Fig.5: Welding of Similar metals

\section{SELECTION OF WELDING PROCESS}

\subsection{Use Friction Welding over other forms of Welding:}

Craig Brown, metallurgical engineering manager at Stork Techni met has performed extensive analysis of friction welded joints. Comparing friction welded to conventional welded joints, Brown states, "In general, the heat affected zone (HAZ) is less extensive and has a narrower width than the HAZ of a conventional weld that incorporates a filler material. HAZ mechanical properties are similar to the base metal, but, depending upon the temperature achieved during welding, the cooling rate and the post-weld thermal treatment, all three can change the weld properties. If all are controlled correctly, welds will have the necessary integrity."

\section{Key Advantages of Friction Welding}

1. Joint Strength Equal to or Stronger than the parent material, 2. Lower Cost per Weld (Typically 75\% less welding time required vs MIG), 3. Weld Preparation is less costly. 4. Weld Joints are very reliable. 5. Dissimilar Materials can be welded without filler material. 6. Controllable Heat Affected Zone (HAZ) 7. $100 \%$ Weld 8. Process provides SelfCleaning/Decontamination of Weld Interface.

\section{EXPERIMENTATION}

\subsection{Experiment}

The main aim of the project is to provide with a variety of friction welding parameters suitable for different kinds of materials in the cases of the welds being carried out between both similar and dissimilar metals and materials as shown in Fig.6.

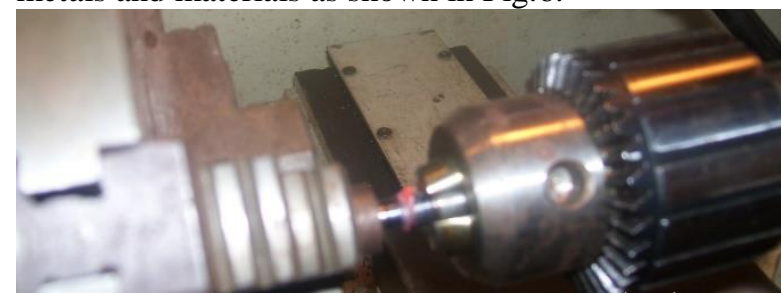

Fig.6: Friction welding on Similar Metals (Mild SteelMild Steel)

The process of Friction Welding, in practice, is accomplished in three phases:

\section{Before Welding}

1. Parts are mounted in the Friction Welder

2. Rotating Part is spun up to speed of 1,000 RPM.

Phase1 (First Friction)

1. Parts are rubbing together, at low force, to accomplish a clean-up of the two surfaces

To be welded.

2. The force applied during First Friction is $\sim 30 \%$ of the Second Friction.

Phase 2 (Second Friction)

1. The increased pressure brought about during second friction causes the metal to become "plastic" and flows out ward from center to form the characteristic "Flash".

2. Once the designed Flash is accomplished, the rotation is rapidly stopped. The Process

then moves to the Forge Phase.

Phase 3 (Forge)

1. The Forge is caused by the application of the highest of the three process pressures.

The forge phase takes place while the components are at a complete stop.

2. The pressure is maintained until the weld joints sufficiently cooled.

3. This step promotes refinement of the microstructure of the weld.

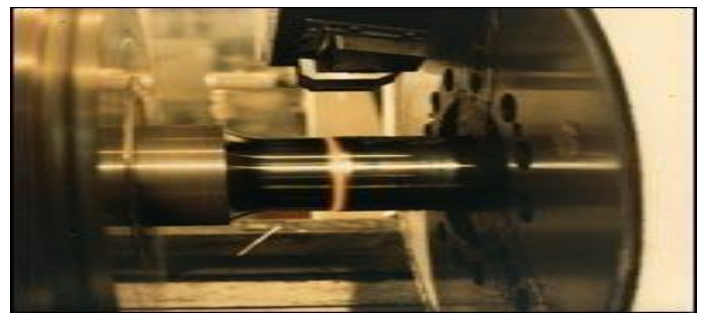

Fig.7: Phase 1

Low temp interface heat cycle by spinning one component against another stationary component. 


\section{Available online at www.ijrat.org}

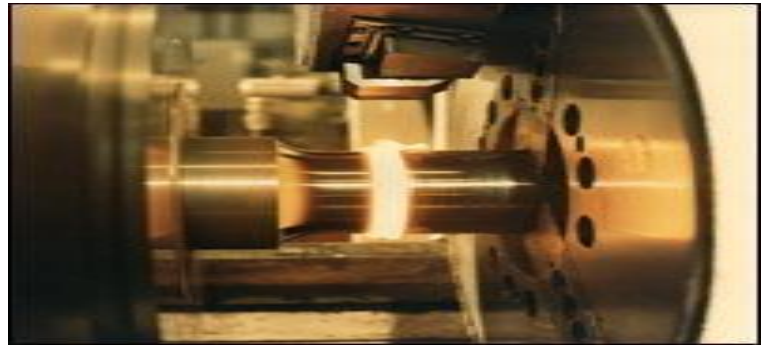

Fig.8: Phase 2

Solid forging cycle showing displaced plastic state material when final axial forging force is applied.

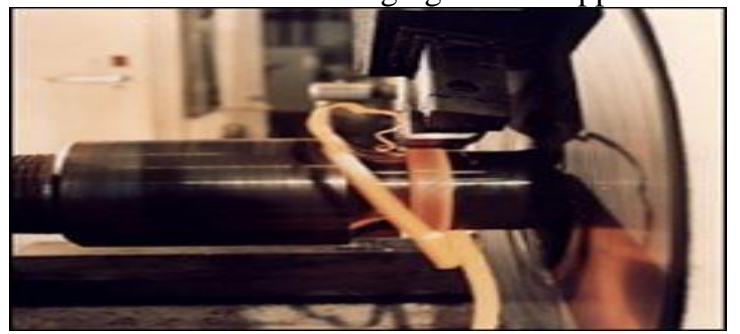

Fig.9: Phase 3

Friction welding is a low temperature, solid state welding process producing repeatable, $\mathrm{CNC}$ controlled high quality weld joints. Interface temperature is raised to a plastic state level through friction by spinning one part against another, and then applying a forging force to bond the weldment. By producing a full cross-sectional surface forging, our process yields a very high strength, low stress weld with no porosity, and, in most cases, eliminates the need for costly pre-machining. Joint strength is equal to parent material strength.

\section{HARDWARE SPECIFICATIONS \\ Hardware Specifications}

A lathe machine is shown in below Figure and its specifications are given below.

\section{Machine}

: Unitech

Lathe Machine

Configuration : M250.

Nominal forge load : 250 tons.

Nominal forge pressure: $2500 \mathrm{KN}$.

Typical spindle power: $186 \mathrm{~kW}$.

Range weldable : $65-150 \mathrm{~mm}$.

Max. Tube diameter $\quad: 400 \mathrm{~mm}$

Max.Length in chuck: $1120 \mathrm{~mm}$

Max.Weld area : $18000 \mathrm{~mm}^{2}$

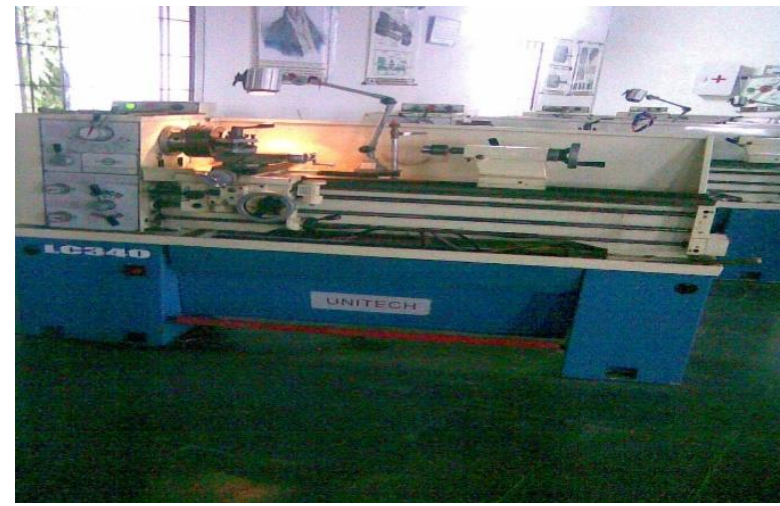

Fig.10: Lathe Machine in lab

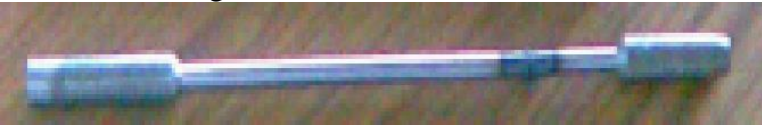

Fig.11: A photograph of an inertia welded component.

\section{RESULTS AND DISCUSSION}

After the experimentation, the following tests were carried out and results were drawn from the same.

\subsection{Tensile Test}

After welding was performed, tensile tests were carried out to evaluate the mechanical properties of junctures, beside parameter settings, optimization and qualification of welding procedures and processes. The welded specimens were machined subjected to tensile tests on a machine brand UTK-4DE (2005/1281) with a capacity $400 \mathrm{kN}$ at room temperature of $25^{\circ} \mathrm{C}$. The values after test are as shown in Figure 6.1.

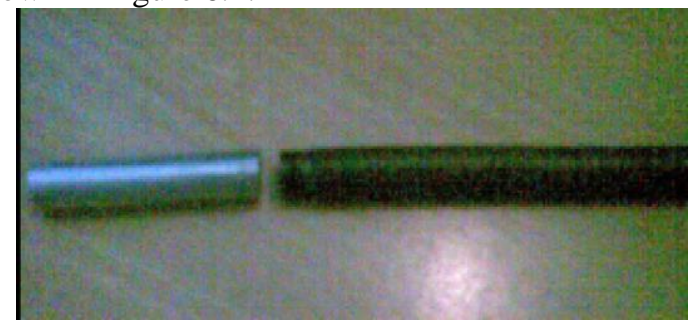

The results of the tensile tests for different welding parameters $\left(t_{1}, t_{2}\right.$, and $\left.P_{2}\right)$ are shown in Table 3 . Effects of upset time and upset pressure on the strength of junctures were examined in welding of equal diameter parts, friction time was kept constant. The strength of junctures was determined by tensile tests, and the results were compared to those of fully machined specimens. Tensile strength of the junctures was estimated dividing the ultimate load by area of 8 $\mathrm{mm}$ diameter specimen. The fracture occurred at the interface of the dissimilar metal weld joint, strength of the weld joint was lesser than tensile strength of H30 aluminum $270 \mathrm{Mpa}$ there was an unbounded region around the center of the fracture surface, although the aluminum alloy was partially bonded to the mild steel. The unbounded region is defined as the region where the adhesion between the materials and inter diffusion of each element are insufficient, and elements are not 


\section{Available online at www.ijrat.org}

metallically bonded to each other. i.e., in sufficient upset pressure and upset time meant that the faying surfaces had not entirely reached up to the certain limit where the amount of axial forging pressure and the time required reaching the bonding temperature therefore, an unbounded region remained at the centre of the weld interface.

Only the outer region was bonded because the temperature here was higher than that of the inner region in the forging stage. The obtained results are plotted between tensile strength versus upset pressure and upset time and are shown graphically in Figure 6.3, 6.4 and Figure 6.5.

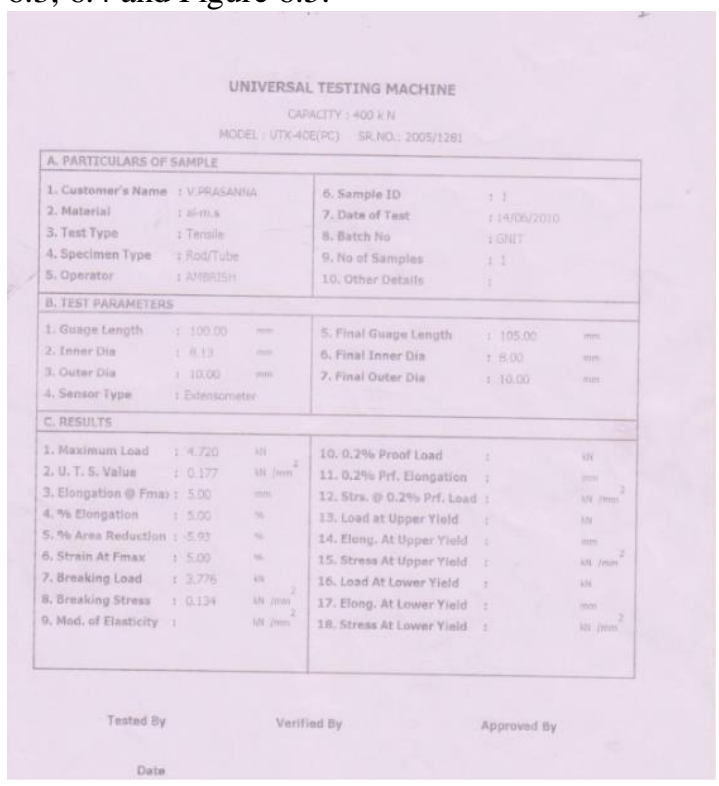

Various graphs are plotted for each of the following as shown in Figure 6.3, 6.4 and 6.5.

Table III: Tensile test values

\begin{tabular}{|l|l|l|l|l|l}
\hline Trails & Pressure & Time & $\begin{array}{l}\text { Upset } \\
\text { Pressure }\end{array}$ & $\begin{array}{l}\text { Upset } \\
\text { Time }\end{array}$ & $\begin{array}{l}\text { Tensile } \\
\text { strength }\end{array}$ \\
\hline 1 & 80 & 4 & 140 & 4 & 134.2 \\
\hline 2 & 80 & 4 & 160 & 5 & 177.8 \\
\hline 3 & 80 & 4 & 200 & 6 & 153.6 \\
\hline 4 & 80 & 4 & 300 & 7 & 0 \\
\hline
\end{tabular}

As upset time and upset pressure for the junctures passes through a maximum, when upset time and upset pressure for the junctures are further increased, tensile strength of the joints decreases and finally fails due to high axial upset pressure in which just piercing of mild steel into the aluminum took place with zero mechanical locking or elemental bonding between two dissimilar metals. Thus, it is shown that upset time and upset pressure have a direct effect on joint y time and upset pressure affect cue of the metals the weld reduces the junctures quality, but it was slightly softened.

The fracture mechanism of junctures with a shorter time may be different from that of junctures with a longer upset time. The initial step was to examine fracture surfaces for any noticeable difference in fracture mechanism between unsound junctures with lesser and higher upset pressures and upset times. Figure 5.9 shows the specimens after tensile test.

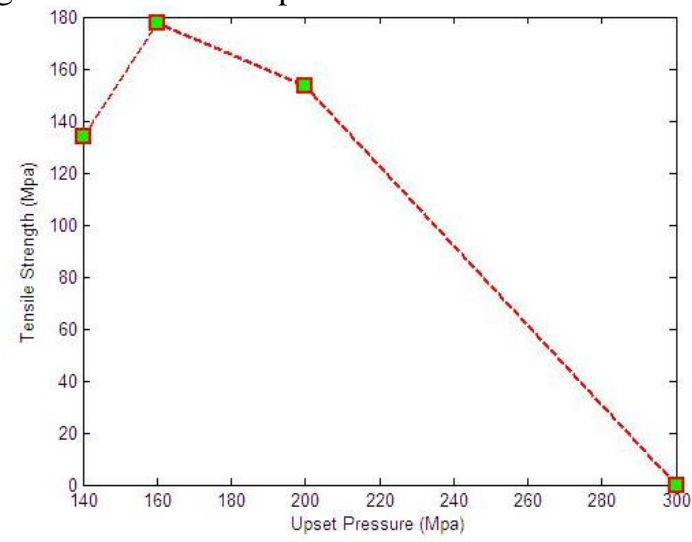

Figure 6.3: Relation between tensile strength and upset Pressure

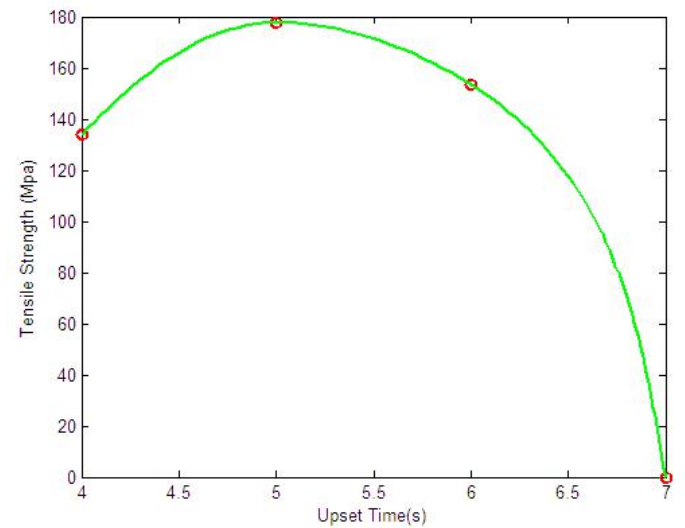

Figure 6.4: Relation between tensile strength and upset time.

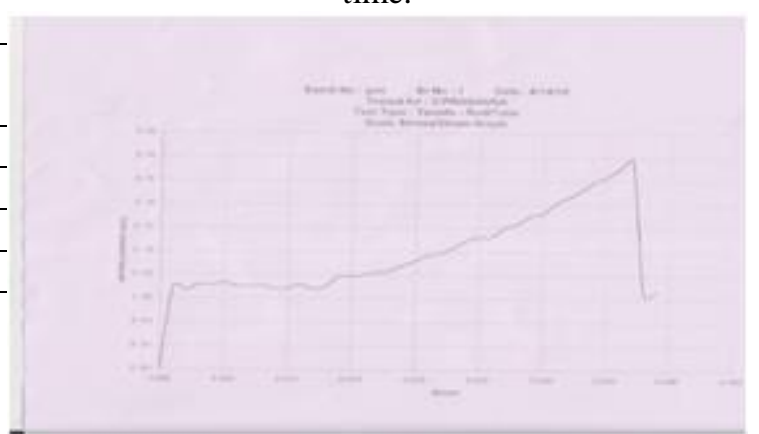

\subsection{Microstructure Test}

Figure 6.5: Basic stress strain graph

The junctures were cut in the transverse weld, embedded in an array of Bakelite, polished and examined in the region of the interfaces on aluminum to mild steel under a matascan metallurgical microscope (Jyothi Spectro Analysis (P) Ltd., Hyderabad, INDIA). Figure 6.6 shows a photomicrograph of the junctures. between $\mathrm{H} 30$ aluminum and BS970 mild steel taken in the central region of the sample with an increase of $100 \mathrm{X}$. The interface region is characterized by a 


\section{Available online at www.ijrat.org}

straight line with some imperfections under $\mathrm{t}$ he friction welding process. Both in the aluminum and mild steel side's micro structural changes are not observed ne ar the interface region as it occurs in fusion welding processes. All plastic deformation resulting from the parameters used in the process occurred in the $\mathrm{H} 30$ aluminum, due to the fact that this material has lower strength and lower hot forging temperature.

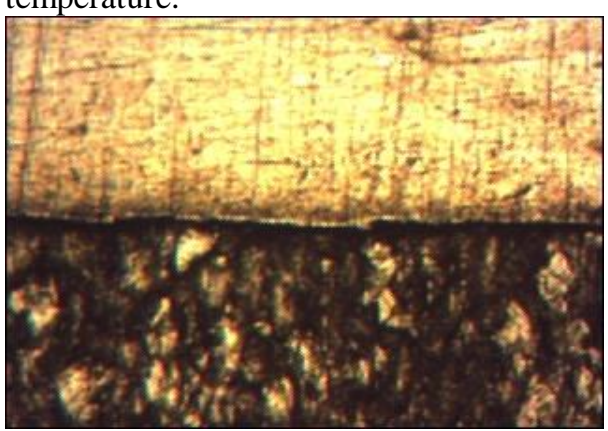

Figure 6.6: Mild Steel- Aluminum @ 100X

\subsection{Hardness Test:}

The Rockwell hardness test method measures the permanent depth of indentation produced by a force or load on an indenter. This load rep resents the zero or reference position that breaks thro ugh the surface to reduce the effects of surface finish. A conical diamond indenter with a round trip is used for hard materials and minor load is $10 \mathrm{kgf}$ and major load is $60-150 \mathrm{kgf}$.

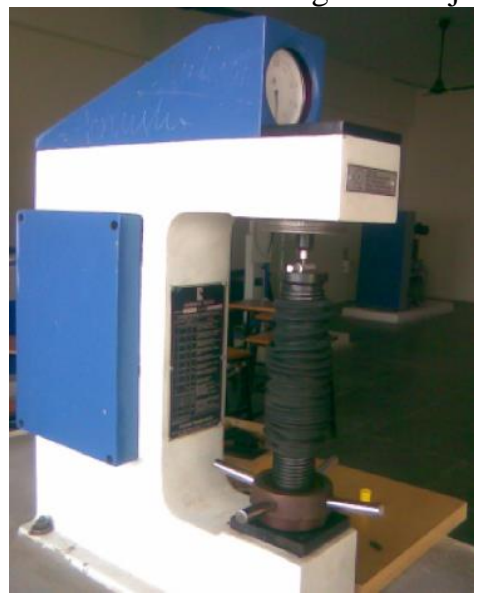

Figure 6.8: Rockwell Hardness test

Rockwell number was calculated on B-scale of hardness machine values as shown in the Table 4 . The variations in the hardness numbers different values of speed and feed rate values of hardness number was increasing and decreasing during testing. The Rockwell hardness test was conducted for measuring hardness along the weld zone.

Figure 6.8 shows the apparatus on which the test was conducted and the sample after indention is shown in the Figure 6.9 as shown.

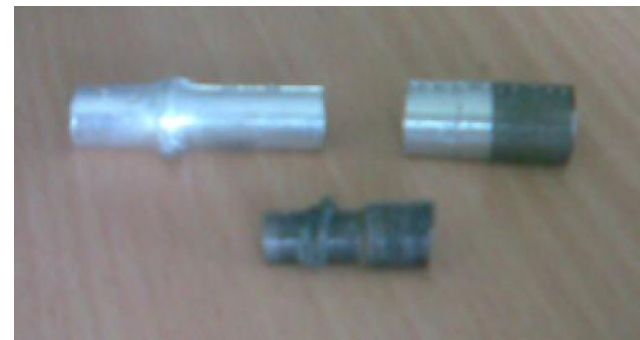

Figure 6.9: Specimens For Hardness Test. (Aluminum - Aluminum ,Aluminum - Mild Steel , And Mild Steel - Mild Steel )

From results of the hardness testing it is observed that maximum hardness number obtained for Rockwell for sample I, using cylindrical tool at speed $3000 \mathrm{rpm}$ and feed $30 \mathrm{~mm} / \mathrm{sec}$.

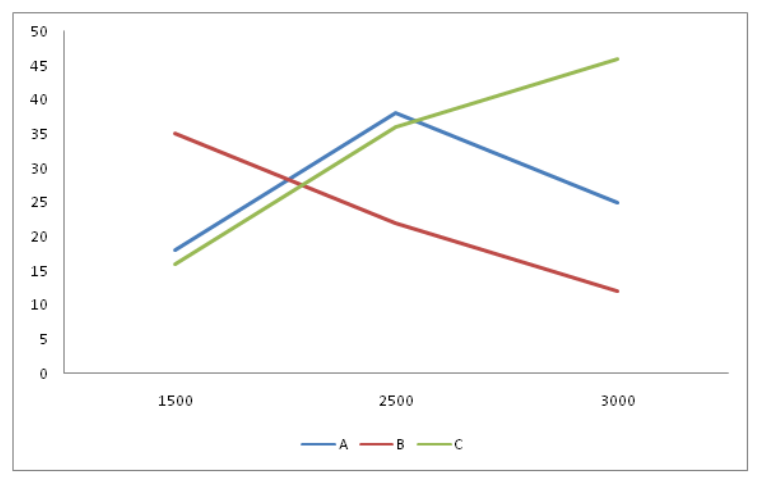

Figure 6.10: Graph between speed and Rockwells hardness number

\section{CONCLUSION}

Please From the results of the test conducted, we can conclude that:

1. Dissimilar metals can be joined by using the friction welding process.

2. The material properties like bond integrity, shear strength, hardness distribution will not change.

3. Rockwell hardness number of a welded material when measured on B-scale obtained is " 46 " which is greater than the base material.

4. The heat affected zone is well fused.

5. Cost of the process reduces considerably when compared to other welding processes.

6. Most advisable process among the existing process.

7. Friction welding has been successfully used in automotive and aerospace industries.

8. Tensile strength for BS970 mild steel and H30 aluminium after welding is 270MPA which yielded positive result when compared to those of base material.

9. The joint strength increases to 180MPA and then decreases to zero when upset time and upset pressure increases.

nt no defects.

11. Efficiency of the weld material increases by $15 \%$ when compared to other welding processes. 


\section{Available online at www.ijrat.org}

Friction Welding is an extremely reliable and cost effective method of joining metal parts. Friction Welding is a well-established technology with applications in industries such as Agriculture; Automotive; Aerospace; Nuclear to name a few. Swan son Industries has the ability to supply Friction Welded services and the engineering support required for the application. Friction Welding is accomplished by rubbing two components together under a load. This rubbing is achieved by forcing a non-rotating component against aRotating component. Friction Welding is suited for welding similar or dissimilar metal(With different melting temperatures) together.

include a brief summary of the possible clinical implications of your work in the conclusion section. Although a conclusion may review the main points of the paper, do not replicate the abstract as the conclusion. Consider elaborating on the translational importance of the work or suggest applications and extensions.

\section{REFERENCES}

[1] Fukumoto S, Inuki T, Tsubakino H, Okita K, Aritoshi M, Tomita T, Evaluation of friction weld interface of aluminum to austenitic stainless steel joint, Materials Science and Technology, 1997: Vol. 13, pp. 679-686.

[2] Fuji A, Kimura M, North T H, Ameyama K, Aki M, Mechanical properties of titanium - 5083 aluminum alloy friction joints, Materials Science and Technology, 1997:Vol. 13, pp. 673-678.

[3] Maldonado-Zepeda, C., 2001, The effect of interlayers on dissimilar friction weld properties, $\mathrm{PhD}$ thesis, University of Toronto, Canada.

[4] Ylbas, B.S, Sahin Z, Kahraman N, Al-Garni A Z, Friction welding of $\mathrm{St}-\mathrm{Al}$ and $\mathrm{Al}-\mathrm{Cu}$ materials, Journal of Materials Processing Technology, 1995:Vol. 49, pp. 431-443.

[5] Fukumoto S, Tsubakino S, Okita K, Aritoshi M, Tomita T, Friction welding process of 5052 aluminum alloy to 304 stainless steel. Materials Science and Technology, 1999:Vol. 15, pp.10801086.

[6] Elliot. S, Wallach. E. R, Joining aluminum to steel, part-1 Diffusion bonding, Metal Construction 13(3), 1981: pp. 167-171.

[7] J. E. Hatch, Aluminium properties and Physical Metallurgy, American Society for Metals, 1984: pp. 2

[8] Schwartz M.M., "Metals Joining Manual", McGraw-Hill Inc., 1979.

[9] Parmar R.S., "Welding Processes and Technology", Khanna Publishers, 